\title{
Microsclerotial Enumeration, Size, and Survival of Calonectria pseudonaviculata
}

\author{
Xiao Yang ${ }^{\dagger}$ and Chuanxue Hong, Hampton Roads Agricultural Research and Extension Center, Virginia Tech, Virginia Beach, VA, 23455
}

\begin{abstract}
Boxwood blight caused by Calonectria pseudonaviculata $(C p s)$ is an emerging disease in the United States. Understanding the biology and survival of microsclerotia, the resting propagules of $C p s$, is important to managing the disease and restoring Cps-infested sites. In this study, an image-analyzing software (OpenCFU) was adapted to enumerate microsclerotia produced in culture plates. Microsclerotial counts increased with time up to 42 days while their size continued to grow for

70 days. Additionally, younger microsclerotia were less sensitive to extreme temperatures of -10 and $40^{\circ} \mathrm{C}$ than older ones. For instance, 21day-old microsclerotia survived at almost twice the rate of 70-day-old ones after a 24 -h exposure to $-10^{\circ} \mathrm{C}$. Likewise, the 21-day-old microsclerotia survived at much greater rates than 70-day-old ones (50 to $70 \%$ versus $<10 \%$ ) after a $24-\mathrm{h}$ exposure to $40^{\circ} \mathrm{C}$. The practical implications of these results are discussed.
\end{abstract}

Boxwood blight caused by Calonectria pseudonaviculata $(\mathrm{Cps})$ (Crous, J.Z. Groenew. \& C.F. Hill) L. Lombard, M.J. Wingf. \& Crous (anamorph: Cylindrocladium pseudonaviculatum Crous, J.Z. Groenew. \& C.F. Hill) is an emerging disease. This disease was first observed in the United Kingdom in 1994 (Henricot 2006) and in the United States in 2011 (Ivors et al. 2012). It has spread to more than 24 states in the U.S. (Iriarte et al. 2016; Ivors et al. 2012; Malapi-Wight et al. 2014; Ward Gauthier et al. 2016) and resulted in severe losses to the ornamental horticulture industry, historical gardens, and landscapes (Avenot et al. 2017; Palmer and Shishkoff 2014; Tripp 2016). Its major diagnostic symptoms include dark brown leaf spots, black streaks on stem, and rapid defoliation.

Microsclerotium as the survival structure of $C p s$ is important to the disease cycle of boxwood blight. Henricot et al. (2008) reported that Cps could survive in the litter for at least 5 years. $C p s$ microsclerotia were first captured under the microscope by Weeda and Dart (2012). In a follow-up study, Dart et al. (2015) demonstrated that after being buried in the soil for 40 weeks, Cps microsclerotia had no sign of decline, suggesting this pathogen has a significant soil phase. Shishkoff and Camp (2016) also reported that Cps microsclerotia survived for more than 30 months at 0 to $20^{\circ} \mathrm{C}$, but they died off after 2 and 7 months at 30 and $-10^{\circ} \mathrm{C}$, respectively. Furthermore, Shishkoff (2016) tested microsclerotia of various sizes for their survival after exposure to the sanitizer ZeroTol. The medium (177 to $249 \mu \mathrm{m})$ and small (125 to $177 \mu \mathrm{m})$ microsclerotia had the highest and lowest survival rates, respectively, with large ( 250 to $353 \mu \mathrm{m})$ ones in the middle (Shishkoff 2016). It is unclear whether and how Cps survival under adverse conditions may be associated with its microsclerotial size. More investigations into the biology and survival of $C p s$ microsclerotia are needed in order to develop sustainable solutions to managing boxwood blight.

Production, enumeration, and standardization are among the most important factors affecting $C p s$ microsclerotia research quality and productivity. A method reported by Shishkoff and Camp (2016) is widely used for producing $C p s$ microsclerotia in culture plates. Currently, enumeration on Cps microsclerotia is done manually, which is labor intensive and time consuming. The size of Cps microsclerotia produced in culture plates ranged from 125 to $353 \mu \mathrm{m}$ as reported by

${ }^{\dagger}$ Corresponding author: X. Yang; E-mail: yxiao9@vt.edu

Funding: This research was supported by grants from the 2014 Farm Bill for the fy14 project (14-8130-0282-CA) through the United States Department of Agriculture - Animal and Plant Health Inspection Service.

Accepted for publication 11 December 2017.

() 2018 The American Phytopathological Society
Shishkoff (2016). How microsclerotial size may be related to the culture age, and consequently to Cps survival under extreme environmental conditions are yet to be determined. Thus, the objectives of the present study were to develop a rapid enumeration method for Cps microsclerotia in culture plates and determine how microsclerotial size might change with culture age, as well as how it might affect the survival of microsclerotia under extreme temperatures.

\section{Materials and Methods}

Isolate selection and production of microsclerotia. Five $C p s$ isolates recovered from Buxus and Sarcococca spp. in Virginia and North Carolina, U.S.A., were selected as representative isolates in this study (Table 1). Microsclerotia were produced using a modified method with cellophane (Nakajima et al. 1988; Shishkoff and Camp 2016). An agar block ( $5 \mathrm{~mm}$ in diameter) taken from the actively growing area of a 7- to 14-day-old culture was placed at the center of an autoclaved cellophane sheet (Sigma-Aldrich Co., MO, U.S.A.) covering the surface of $15-\mathrm{ml}$ freshly prepared glucose-yeast extract-tyrosine agar (GYETA) (Hunter 1992) in a 10-cm Petri dish. The culture plates were sealed with Parafilm and incubated in darkness at $20^{\circ} \mathrm{C}$.

Selection of threshold value in OpenCFU. Use of OpenCFU software to count microsclerotia began with photographing the culture plates. The software then recognized and counted circular objects on the digital images while the counting accuracy was improved by a user-defined thresholding procedure (Geissmann 2013). Selection of threshold value in OpenCFU (Geissmann 2013) in this study was accomplished by counting the $C p s$ microsclerotia in the same plates manually and using the software and comparing the counts. Two Cps isolates $11 \mathrm{~A} 01$ and $11 \mathrm{~A} 08$ recovered from different hosts (Table 1) and three culture ages of 21,42 , and 70 days were included in this comparison. On each day, microsclerotia in triplicate plates per isolate were

Table 1. Origin of five representative isolates of Calonectria pseudonaviculata used in this study

\begin{tabular}{|c|c|c|c|c|c|}
\hline Isolate & $\begin{array}{l}\text { Alternative } \\
\text { code }\end{array}$ & Host & Tissue & Location & Year \\
\hline $11 \mathrm{~A} 01$ & VA11-232 & Buxus sempervirens & $\begin{array}{l}\text { Leaf } \\
\text { petiole }\end{array}$ & $\begin{array}{l}\text { Virginia, } \\
\text { U.S.A. }\end{array}$ & 2011 \\
\hline $11 \mathrm{~A} 03$ & BB137 & Buxus sp. & $\begin{array}{l}\text { Leaf } \\
\text { petiole }\end{array}$ & $\begin{array}{l}\text { Virginia, } \\
\text { U.S.A. }\end{array}$ & 2013 \\
\hline $11 \mathrm{~A} 04$ & BB188 & B. sempervirens & Stem & $\begin{array}{l}\text { Virginia, } \\
\text { U.S.A. }\end{array}$ & 2013 \\
\hline 11A05 & BBRC1 & Buxus sp. & n.a. ${ }^{\mathrm{z}}$ & $\begin{array}{l}\text { North } \\
\text { Carolina, } \\
\text { U.S.A. }\end{array}$ & 2014 \\
\hline 11A08 & RL1 & $\begin{array}{l}\text { Sarcococca hookeriana } \\
\text { 'Humilis' }\end{array}$ & Leaf & $\begin{array}{l}\text { Virginia, } \\
\text { U.S.A. }\end{array}$ & 2015 \\
\hline
\end{tabular}

${ }^{\mathrm{z}}$ Not available. 

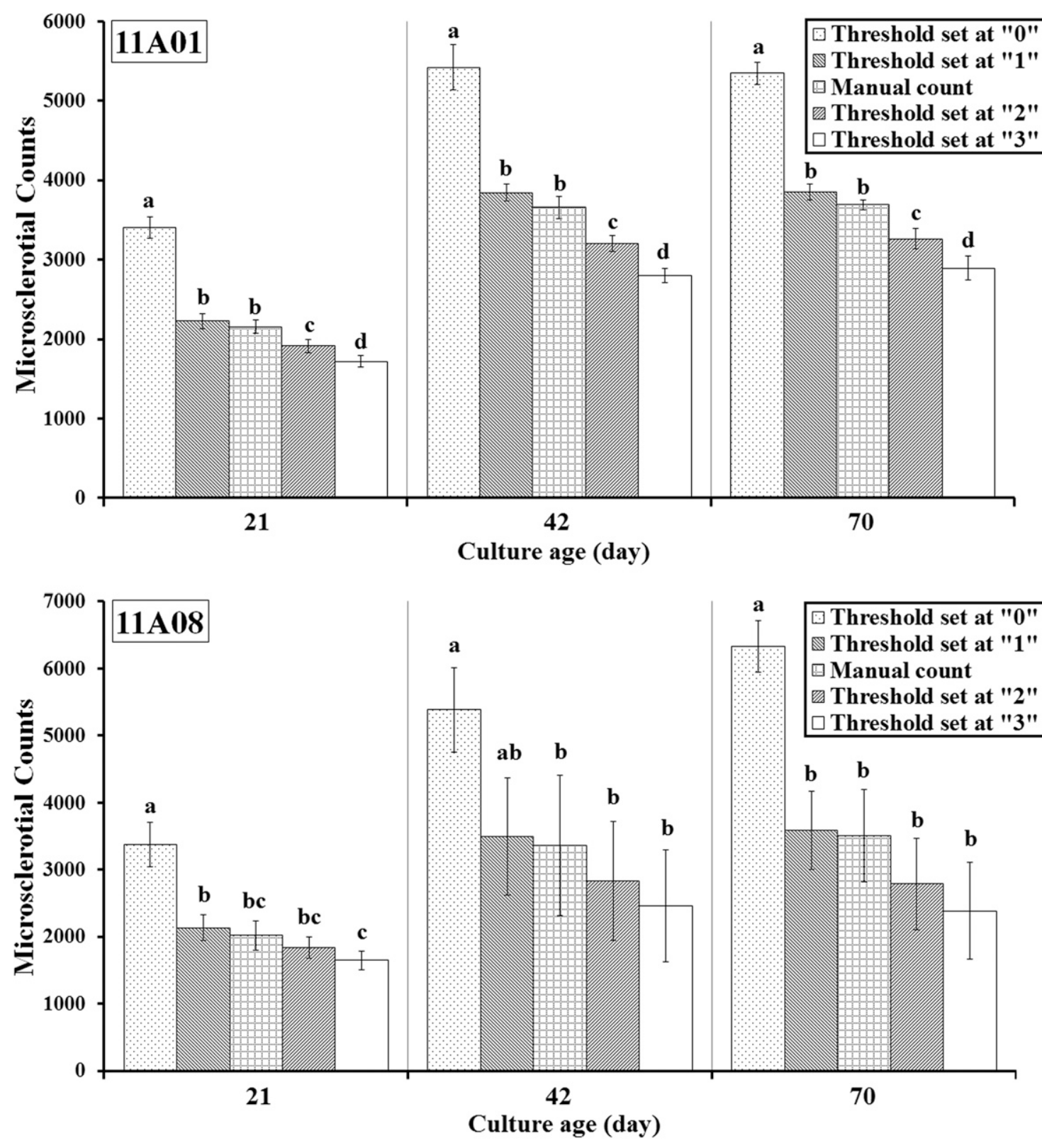

Fig. 1. Comparison of microsclerotial counts obtained manually and using OpenCFU with various threshold settings at $0,1,2$, and 3 . Columns topped with a same letter within each isolate and individual culture ages did not differ significantly according to Waller-Duncan k-ratio $t$-test at $P=0.05$.
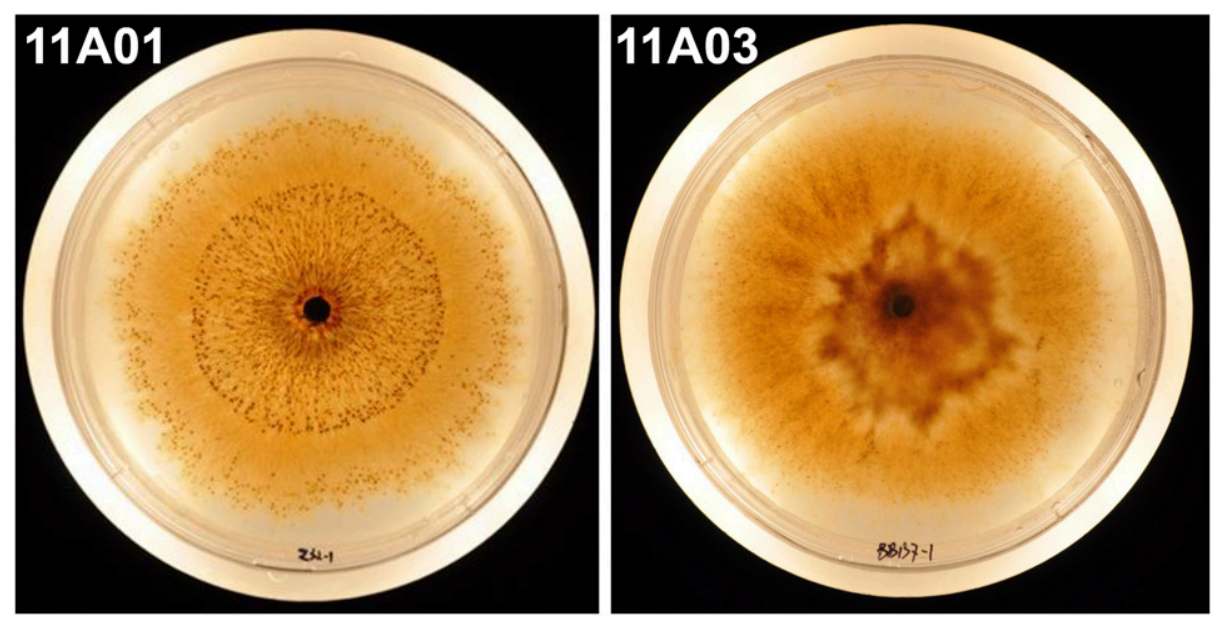

Fig. 2. Colony morphology variations between Calonectria pseudonaviculata isolates $11 \mathrm{~A} 01$ and $11 \mathrm{~A} 03$ on day 42 . Isolate $11 \mathrm{~A} 01$ produced limited to no aerial mycelia, while $11 \mathrm{~A} 03$ produced abundant aerial mycelia, which made photo-analysis by OpenCFU and manually counting impossible. 
manually counted under a dissecting microscope using a click-counter. Cellophane surface of the same plates were photographed 10 times each using a Nikon D90 camera. The camera was stabilized on a stand and set uniformly (manual, ISO 400, F5.6 w/ 40s, incandescent in white balance) throughout the experiment. The culture plates were placed in a photography light tent with background light. Photos were analyzed using OpenCFU (Geissmann 2013) with the radius minimum set at " 1 ," and threshold values at " 0 ," " 1, ," "2," and "3." The resulting counts at various threshold values in OpenCFU were then compared with manual counts. The threshold value at which microsclerotial counts using OpenCFU did not differ from the manual counts was then set in OpenCFU as the standard in the following experiments.

Enumeration of microsclerotia. Five culture plates of each isolate were photographed on days $14,21,28,42,56$, and 70 using the Nikon D90 camera as described above. On each day, 10 photos were taken on the cellophane surface of each culture plate. Microsclerotia captured
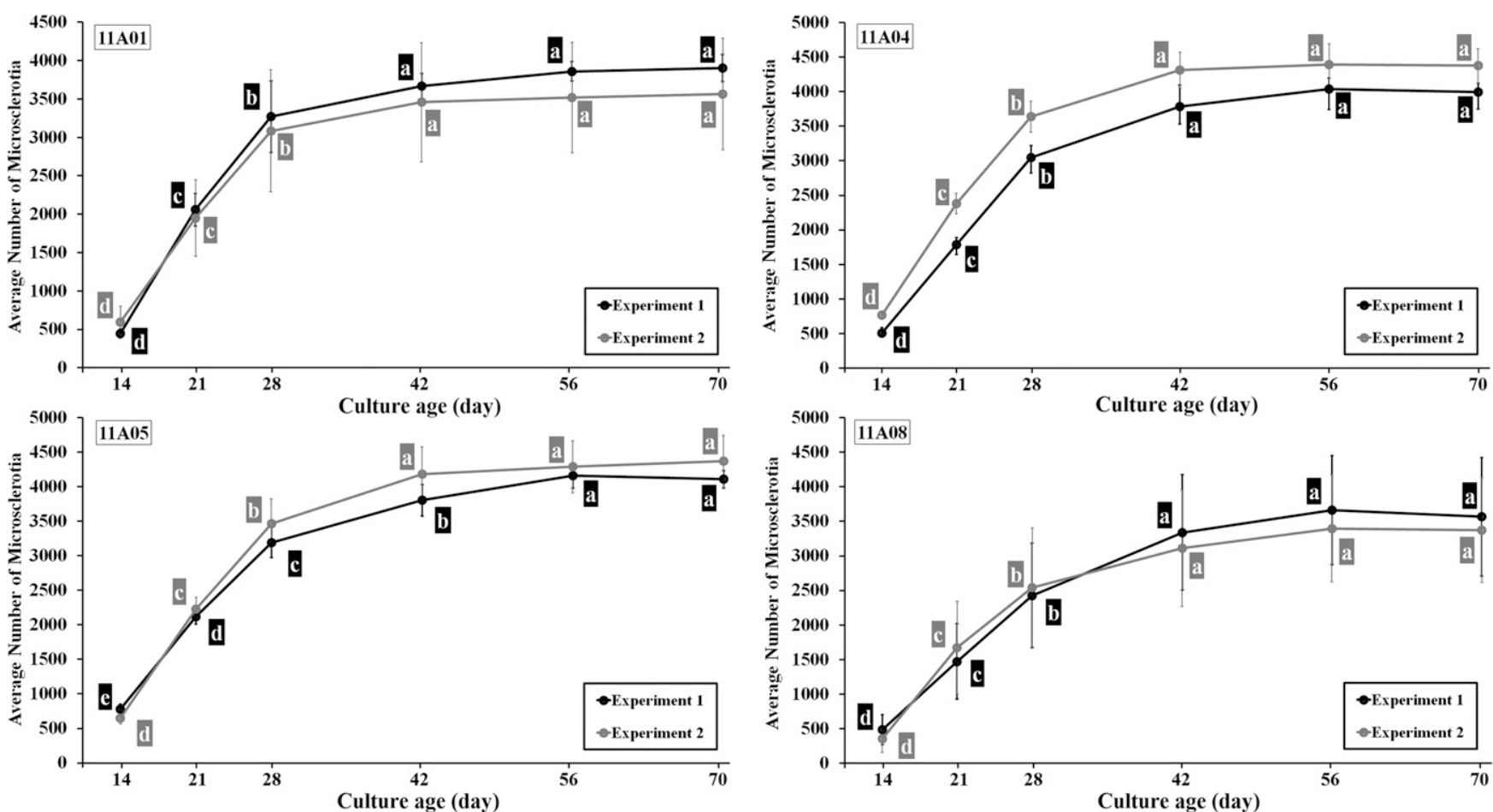

Fig. 3. Microsclerotial production by four Calonectria pseudonaviculata isolates over a 70-day period in two experiments. Microsclerotial counts marked with a same letter within each isolate and experiment did not differ significantly according to Waller-Duncan k-ratio $t$-test at $P=0.05$.
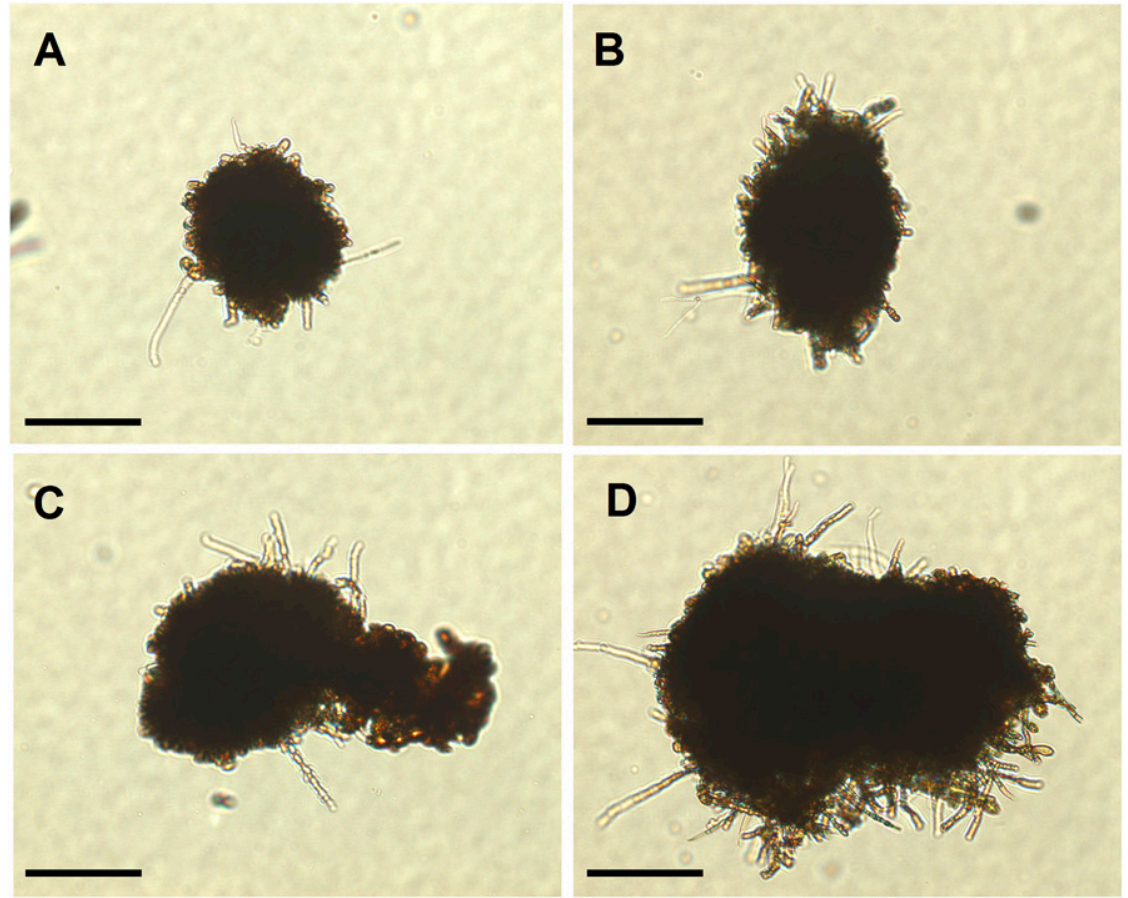

Fig. 4. Morphology of microsclerotia produced by isolate 11A01. A, Globose. B, Ellipsoid. C and D, Irregular-shaped. Bars $=100 \mu \mathrm{m}$. 
in each photo were enumerated in OpenCFU (Geissmann 2013) with threshold value determined above. This experiment was conducted twice.

Size of microsclerotia. Microsclerotia were harvested from triplicate culture plates of isolates 11A01, 11A04, 11A05, and 11A08 on days $21,28,42,56$, and 70 . Two milliliters of distilled water $\left(\mathrm{diH}_{2} \mathrm{O}\right)$ were added to each culture plate. A sterile cotton tipped applicator was used to brush the cellophane surface. The slurry was poured into a 50-ml centrifuge tube. The above procedure was repeated until all microsclerotia on the cellophane were collected. Then, $\mathrm{diH}_{2} \mathrm{O}$ was added to the centrifuge tube until the total volume reached $25 \mathrm{ml}$. The tube containing Cps cultural suspension was vortexed at the maximum speed for $1 \mathrm{~min}$. The agitated slurry was run through two sieves with 355 and $125 \mu \mathrm{m}$ mesh size. The sieves were washed through with $\mathrm{diH}_{2} \mathrm{O}$ several times to remove mycelia and other nontarget structures. Microsclerotia on the $125-\mu \mathrm{m}$ sieve were resuspended in $\mathrm{diH}_{2} \mathrm{O}$ in a 50-ml tube. Fifty randomly selected microsclerotia harvested from each culture plate were examined using a HDMI-2 camera (Southern Microscope, Inc., NC, U.S.A.) connected to a Nikon Labophot-2 microscope and measured for their size using TCapture version 3.9.0.6001. Two measurements were taken perpendicularly for each microsclerotium with the first along its longest axis (length) and the second (width) in the middle on that axis in order to best estimate its size. This experiment was conducted twice.

Survivals of microsclerotia at various temperatures. Microsclerotial suspensions harvested on days $21,28,42,56$, or 70 were pipetted onto Whatman Grade 1 filter papers. The wet filter papers were then blow-dried in a biosafety cabinet for $2 \mathrm{~h}$. Each filter paper with approximately 500 microsclerotia harvested from each culture plate was cut into three equal sections, which were then incubated for $24 \mathrm{~h}$ at $-10,20$, and $40^{\circ} \mathrm{C}$, respectively. Microsclerotia were then separated from each filter paper section using sterile cotton tipped applicators and plated onto triplicate Petri dishes containing $15 \mathrm{ml}$ of freshly prepared acidified peptone-dextrose agar (PEDA). The PEDA plates containing microsclerotia were placed under ambient light at room temperature $\left(\sim 23^{\circ} \mathrm{C}\right)$ for 10 days. The microsclerotial survival was determined by counting the percentage of germinated microsclerotia among 100 randomly selected microsclerotia on each PEDA plate. This experiment was conducted twice.

Statistical analysis. Basic calculations and descriptive statistics were performed using Microsoft Excel 2016. Analysis of variance was performed using R statistical software version 3.1.3 (R Core Team 2015) to determine the difference in results between repeat experiments, among representative isolates, replicates, and other factors. Waller-Duncan k-ratio $t$-test was performed to provide grouping using the package 'agricolae' (de Mendiburu 2015) in R. The significance levels in this study were set at $0.05(5 \%)$.

\section{Results}

Threshold value in OpenCFU. There was no difference in microsclerotial counts using OpenCFU among the replicate culture plates
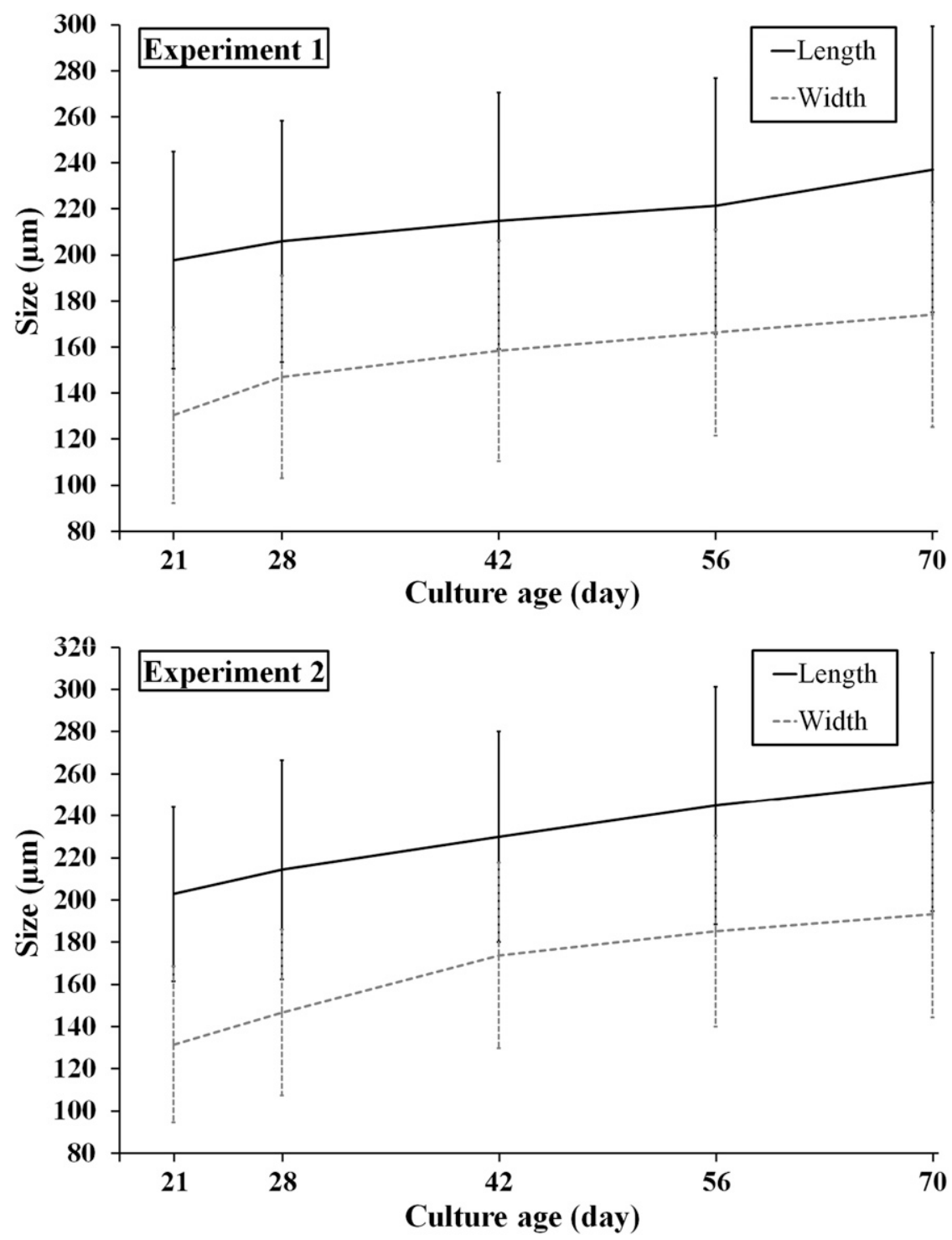

Fig. 5. Microsclerotial size (length and width) of four Calonectria pseudonaviculata isolates increasing with age. 
$(P=0.32)$ and photos $(P=0.99)$. Thus, the average microsclerotial count of 30 photos at each threshold setting in OpenCFU was compared with the manual count of microsclerotia by isolate and culture age.

Microsclerotial counts decreased as the threshold value increased from 0 to 3 in OpenCFU (Fig. 1). For both isolates, microsclerotial counts using OpenCFU at threshold 0 were significantly higher than manual counts at all culture ages (Fig. 1). There was no significant difference in the microsclerotial count between the OpenCFU at threshold 1 and manual counting (Fig. 1). For isolate 11A01, microsclerotial counts using the OpenCFU were significantly lower when threshold was set at 2 and 3 than respective manual counts at all three culture ages. For isolate 11A08, no significant difference was observed between manual counts and those using OpenCFU at threshold values 1, 2, and 3 (Fig. 1). Based on these results, threshold value was set at 1 in OpenCFU in the following enumeration.
Enumeration of microsclerotia. All isolates produced abundant microsclerotia on cellophanes. Isolates $11 \mathrm{~A} 01$ (Fig. 2), 11A04, $11 \mathrm{~A} 05$, and $11 \mathrm{~A} 08$ produced limited to no aerial mycelia. However, isolate 11A03 produced abundant aerial mycelia that completely covered the cellophane surface (Fig. 2). Thus, microsclerotia produced by isolate $11 \mathrm{~A} 03$ could not be counted either manually or using OpenCFU. This isolate was excluded from subsequent experiments.

For the remaining four isolates, there was no difference in the microsclerotial count among five replicate culture plates within isolates $(P=0.21)$ and 10 photos within plates $(P=0.71)$. Microsclerotial counts were significantly different between two repeating experiments $(P<0.01)$, and among four isolates $(P<0.01)$. Microsclerotia produced by all isolates in both experiments rapidly increased with time from day 14 to 28 (Fig. 3). The speed increase slightly declined between days 28 and 42 , although a significant
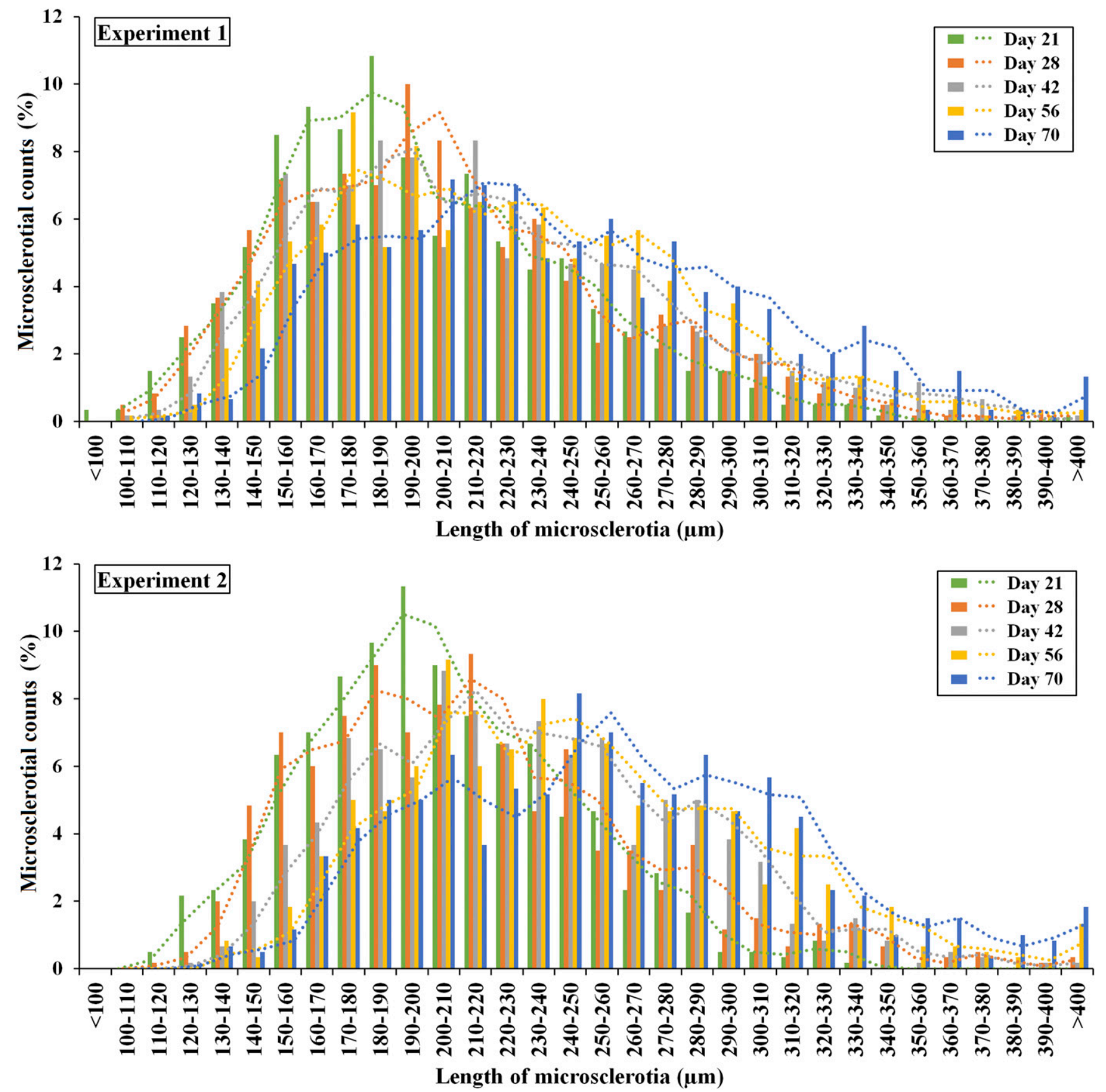

Fig. 6. Length distribution of the 21- to 70-day-old microsclerotia produced by four isolates of Calonectria pseudonaviculata. Columns and moving average trendlines (period set at 2) were plotted in Excel. 
difference in the microsclerotial count was still present between these two culture ages (Fig. 3). Thereafter, the count stabilized between days 42 and 70 . The only exception was that the count of isolate $11 \mathrm{~A} 05$ on day 56 that was significantly higher than on day 42 in the first experiment (Fig. 3).

Size of microsclerotia. Microsclerotia varied greatly in shape (Fig. 4). They could be globose (Fig. 4A), ellipsoid (Fig. 4B), and irregular (Figs. 4C and D). The average length to width ratios were approximately 1.5 on day 21 , and 1.3 on day 70 .

Both microsclerotial length $(P<0.01)$ and width $(P<0.01)$ were significantly different between two experiments. There was no difference in the length among three replicate culture plates $(P=0.56)$ and 50 replicate microsclerotia $(P=0.96)$. Similarly, no difference in the microsclerotial width was observed among culture plates $(P=0.14)$ and replicates $(P=0.18)$.

Microsclerotial length and width increased with time in both experiments. In experiment 1 , the average length of microsclerotia increased from $198 \pm 47 \mu \mathrm{m}$ to $237 \pm 62 \mu \mathrm{m}$ from day 21 to 70 with a $0.8 \mu \mathrm{m}$ daily increase. Similarly, the average width increased from $130 \pm 38 \mu \mathrm{m}$ to $174 \pm 49 \mu \mathrm{m}$ during the same period with a $0.9 \mu \mathrm{m}$ daily increase (Fig. 5). In experiment 2, the average length increased from $203 \pm 41 \mu \mathrm{m}$ to $256 \pm 61 \mu \mathrm{m}$ with a daily increase of $1.1 \mu \mathrm{m}$ and the width increased from $132 \pm 37 \mu \mathrm{m}$ to $193 \pm 49 \mu \mathrm{m}$ with a daily increase of $1.2 \mu \mathrm{m}$ (Fig. 5).

Distributions of microsclerotial length and width are presented in Figures 6 and 7, respectively. On day 21, the most common length ranged from 180 to $190 \mu \mathrm{m}$ in experiment 1 and 190 to $200 \mu \mathrm{m}$ in experiment 2 (Fig. 6) and the most common width ranged from 110 to $120 \mu \mathrm{m}$ in experiment 1 , and 100 to $110 \mu \mathrm{m}$ in experiment 2 (Fig. 7). As expected, the occurrence of larger microsclerotia increased with time. On day 70 , the most common length range was 200 to $230 \mu \mathrm{m}$ in experiment 1 and 240 to $250 \mu \mathrm{m}$ in experiment 2 (Fig. 6). The most common width range was 140 to $170 \mu \mathrm{m}$ in experiment 1 and 150 to $190 \mu \mathrm{m}$ in experiment 2 (Fig. 7).
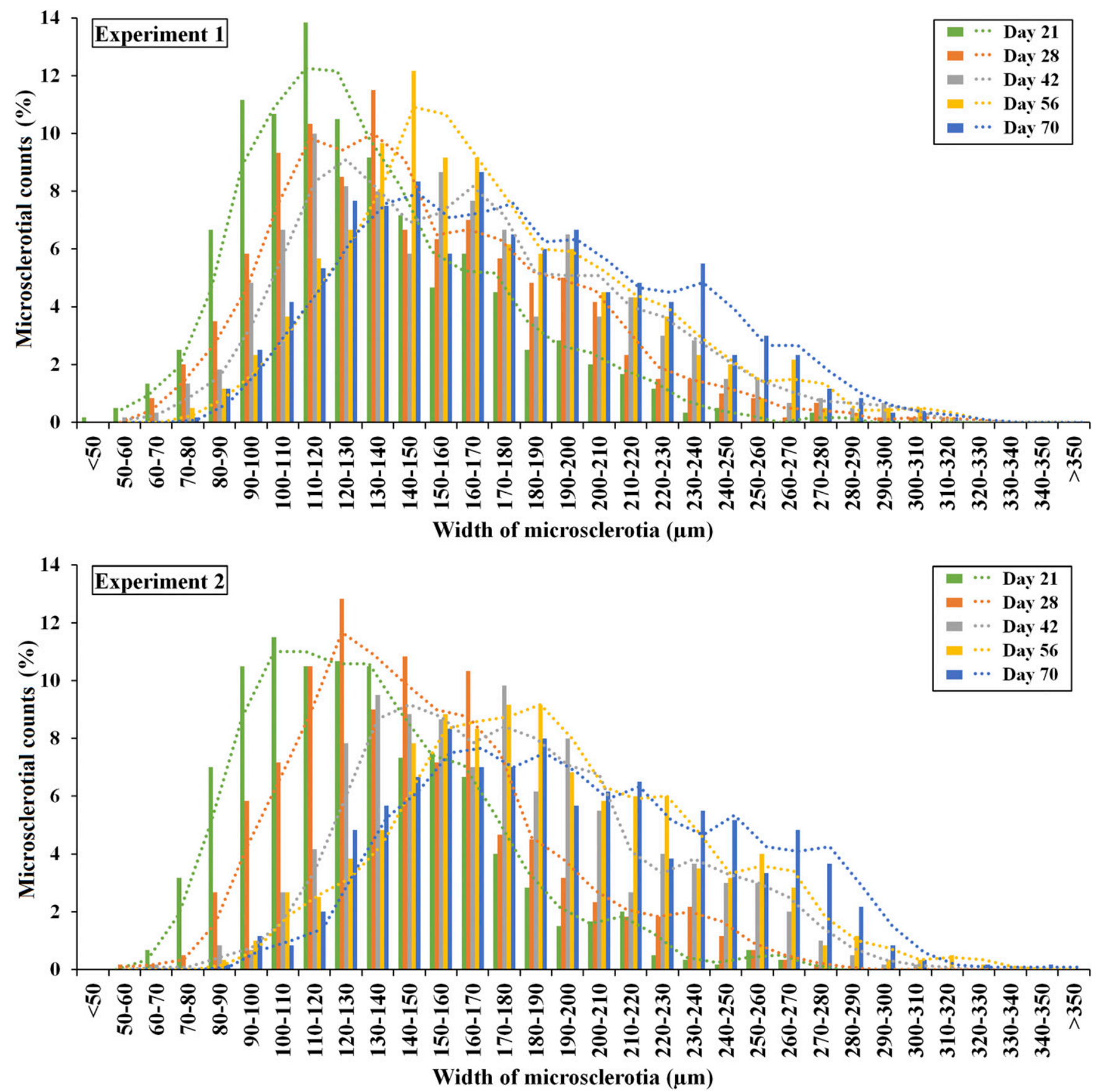

Fig. 7. Width distribution of the 21- to 70-day-old microsclerotia produced by four isolates of Calonectria pseudonaviculata. Columns and moving average trendlines (period set at 2) were plotted in Excel. 
Microsclerotial survival at various temperatures. Microsclerotial survival as measured by the germination rate was significantly different among culture ages $(P<0.01)$ and incubation temperatures $(P<0.01)$. There was no difference in the germination rate between two repeat experiments $(P=0.86)$, among three culture plates $(P=$ $0.95)$ and replicate PEDA plates $(P=0.93)$.

Microsclerotial survival decreased with increasing culture age at $20^{\circ} \mathrm{C}$ (Fig. 8). For instance, the 21- and 28-day-old microsclerotia produced by all four isolates survived at rates of $>98 \%$ (Fig. 8), while those 70-day-old ones produced by isolates 11A04, 11A05, and 11A08 survived at lower rates of 90.9 to $94.3 \%$, except for $11 \mathrm{~A} 01$ at the rate of $98.1 \%$ (Fig. 8).

Exposures to extreme temperatures greatly reduced the microsclerotial survival and this negative impact was more profound on older microsclerotia. After a $24-\mathrm{h}$ exposure to $-10^{\circ} \mathrm{C}, 69.4$ to $82.0 \%$ of the 21-day-old microsclerotia survived, while only 31.5 to $52.9 \%$ of the 70-day-old ones did (Fig. 8). Likewise, after a $24-$ $\mathrm{h}$ exposure to $40^{\circ} \mathrm{C}, 52.4$ to $67.3 \%$ of the 21 -day-old microsclerotia survived, while only 0.9 to $9.8 \%$ of the 70 -day-old ones did (Fig. 8).

\section{Discussion}

This study adapted the image-analyzing software OpenCFU (Geissmann 2013) for improving the enumeration of Cps microsclerotia. The count of microsclerotia produced in culture plates increased with time up to 42 days. While microsclerotia continued to grow in size for up to 70 days, their survival decreased with culture age. These results have several practical implications in future studies on $C p s$ microsclerotium biology and the development of management strategies for boxwood blight.

Adapting OpenCFU greatly expedited microsclerotial enumeration and improved its accuracy. It took more than $2 \mathrm{~h}$ to count 2,000 to 3,000 microsclerotia manually in a single culture plate. It was almost impossible to count the microsclerotia in 20 plates manually on each designated assessment time without sacrificing the counting accuracy. With the adapted OpenCFU setting threshold at 1 in this study, only $<30 \mathrm{~min}$ was required to count microsclerotia in a culture plate. By allowing all required microsclerotial enumeration in a timely manner, this new method certainly will improve research data quality. It also may reduce potential human error that is likely associated with manual counting. This method could be easily adapted for enumeration of (micro)sclerotia produced by other fungi. It must be noted that selection of threshold value is crucial to the accuracy of microsclerotial enumeration when adapting this method, and therefore so is the initial manual counts upon which the threshold value is set.

Substantial variation was found in the size of $C p s$ microsclerotia. The microsclerotia length ranged from approximately 100 to $450 \mu \mathrm{m}$ (Fig. 6) and their width from approximately 50 to $350 \mu \mathrm{m}$ (Fig. 7). This size range appeared wider than the previous report (Shishkoff 2016). Also, microsclerotial size increased with time up to 70 days in this study. It would be interesting to measure the size of microsclerotia that are older than 70 days to determine their maximum size. Additionally, the microsclerotial size distributions (Figs. 6 and 7) indicate that culture age is critical to the productivity in experiments that harvest microsclerotia of certain sizes. Furthermore, Shishkoff (2016) reported that microsclerotia produced in leaf tissues were significantly smaller than those produced on cellophane sheets in culture plates. Future studies are warranted to determine the size distribution of microsclerotia produced in plant tissues.

Survival of $C p s$ microsclerotia could be reduced by a short exposure to high temperatures. For instance, the survival rates of microsclerotia were significantly reduced to $<10 \%$ after a 24 -h exposure to $40^{\circ} \mathrm{C}$ (Fig. 8). Such temperature influence on the survival of Cps microsclerotia was also reported by Shishkoff and Camp (2016). These results indicate that heat treatments, such as solarization and composting, are promising measures to eradicate $C p s$ microsclerotia and restore infested sites. Solarization has been used to eradicate resting propagules of other Calonectria spp. (Polizzi et al. 2003; Vitale et al. 2013), while a composting system to eradicate $C p s$ has been under evaluation (Harvey et al. 2015). Additional studies are needed to determine the specifics for developing a heattreatment protocol, such as the most timely and economically effective combination of temperature and duration, as both a 2-month incubation at $30^{\circ} \mathrm{C}$ (Shishkoff and Camp 2016) and a 24-h exposure to $40^{\circ} \mathrm{C}$ in this study eradicated or greatly reduced the survival of $\mathrm{Cps}$ microsclerotia. It is worth mentioning that microsclerotia in plant tissues appeared to survive better than those produced in vitro (Shishkoff and Camp 2016). Because $40^{\circ} \mathrm{C}$ was not included as a treatment in Shishkoff and Camp (2016), nor microsclerotia produced in plant tissues in this study, future studies are warranted to provide additional
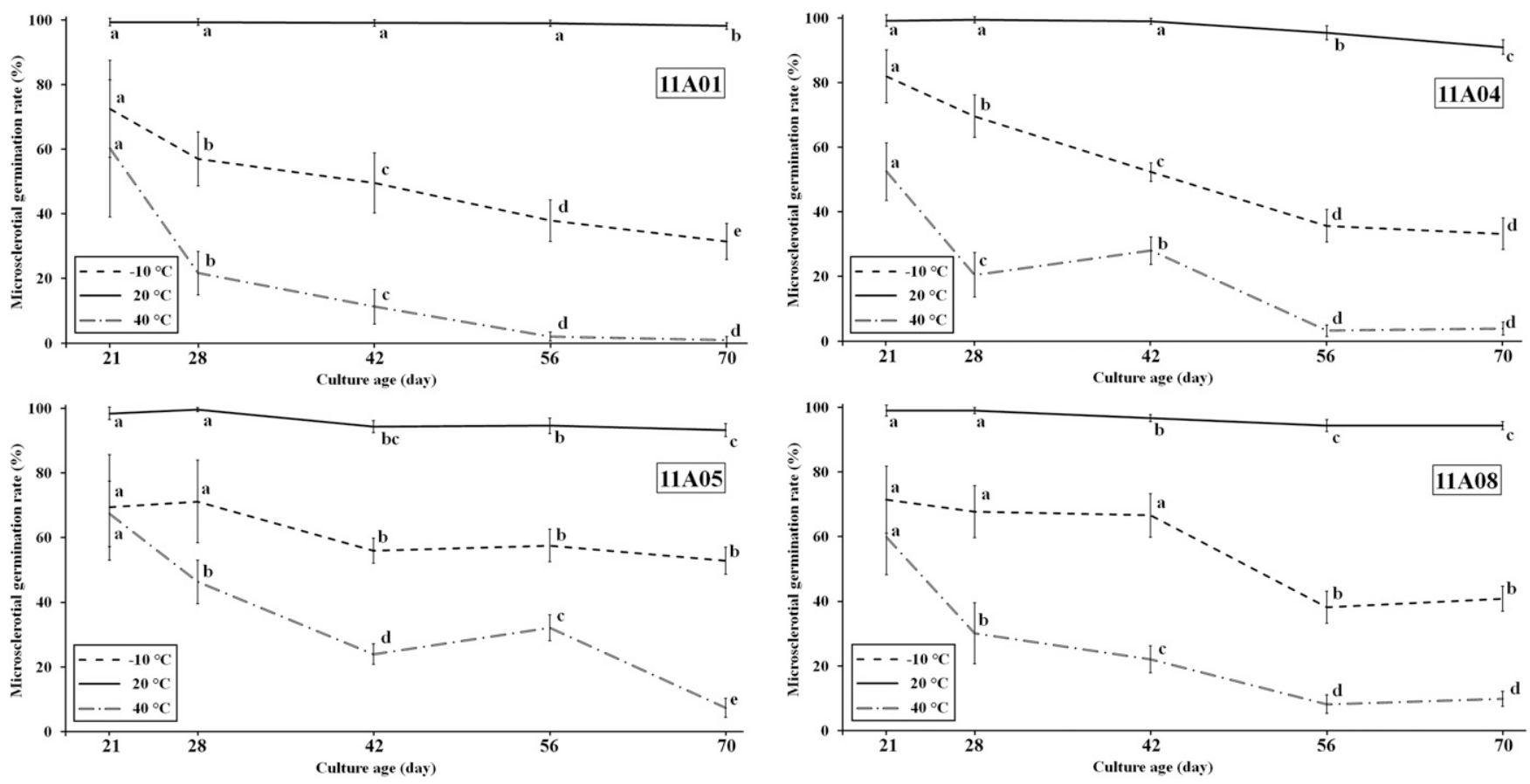

Fig. 8. Germination rates of 21 - to 70 -day-old microsclerotia of four Calonectria pseudonaviculata isolates after a $24-\mathrm{h}$ exposure to $20,-10$, and $40^{\circ} \mathrm{C}$. Germination rates marked with a same letter within each isolate and temperature treatment did not differ significantly according to Waller-Duncan k-ratio $t$-test at $P=0.05$. 
information on the survival of microsclerotia produced in situ and their sensitivity to $40^{\circ} \mathrm{C}$.

Although microsclerotial survival was impaired at $-10^{\circ} \mathrm{C}$, this low temperature was not as efficient as the high temperature in reducing microsclerotial survival. After a 24 -h exposure to $-10^{\circ} \mathrm{C}, \mathrm{Cps}$ microsclerotia survived at the rate of 40 to $80 \%$ (Fig. 8). In another study, it took 7 months to eradicate $C p s$ microsclerotia at $-10^{\circ} \mathrm{C}$, while only 2 months at $30^{\circ} \mathrm{C}$ (Shishkoff and Camp 2016). Furthermore, it is unknown whether this low temperature truly resulted in mortality or merely induced the dormancy of microsclerotia. Previous studies reported that low temperatures could induce dormancy in fungal resting propagules such as microsclerotia of Calonectria crotalaria (Griffin et al. 1978) and sclerotia of Sclerotinia sclerotiorum (Dillard et al. 1995). It remained unknown if non-germinated microsclerotia in this study were dead or became dormant after exposure to $-10^{\circ} \mathrm{C}$, knowing that special measures could be required to break such dormancy (Dillard et al. 1995).

The fact that younger microsclerotia survived better at extreme temperatures than older ones clearly indicates that longer exposure times in the heat treatment are required to eradicate younger microsclerotia than the older ones. Considering the older microsclerotia are larger in size, this finding may also indicate a negative correlation between microsclerotial size and their survival at extreme temperatures, although more investigations are warranted to further explore the potential correlation between the microsclerotia size and survival under other adverse environmental conditions.

\section{Literature Cited}

Avenot, H. F., King, C., Edwards, T. P., Baudoin, A., and Hong, C. X. 2017. Effects of inoculum dose, temperature, cultivar, and interrupted leaf wetness period on infection of boxwood by Calonectria pseudonaviculata. Plant Dis. 101:866-873.

Dart, N., Hong, C. X., Craig, C. A., Fry, J. T., and Hu, X. R. 2015. Soil inoculum production, survival, and infectivity of the boxwood blight pathogen, Calonectria pseudonaviculata. Plant Dis. 99:1689-1694.

de Mendiburu, F. 2015. agricolae: Statistical procedures for agricultural research. R package version 1.2-3. https://cran.r-project.org/web/packages/agricolae/index.html

Dillard, H. R., Ludwig, J. W., and Hunter, J. E. 1995. Conditioning sclerotia of Sclerotinia sclerotiorum for carpogenic germination. Plant Dis. 79:411-415.

Geissmann, Q. 2013. OpenCFU, a new free and open-source software to count cell colonies and other circular objects. PLoS One 8:e54072.

Griffin, G. J., Roth, D. A., and Powell, N. L. 1978. Physical factors that influence the recovery of microsclerotium populations of Cylindrocladium crotalariae from naturally infested soils. Phytopathology 68:887-891.

Harvey, R., Davis, D., and Pecchia, J. 2015. Does composting eradicate the pathogen responsible for boxwood blight? An outline of future investigations.
Pages 211-215 in: Proceedings of the 2014 Annual Meeting of the International Plant Propagators Society, vol. 1085. C. W. Heuser, ed.

Henricot, B. 2006. Box blight rampages onward. Plantsman (Lond., Engl.) 5: 153-157.

Henricot, B., Gorton, C., Denton, G., and Denton, J. 2008. Studies on the control of Cylindrocladium buxicola using fungicides and host resistance. Plant Dis. 92: 1273-1279.

Hunter, B. B. 1992. Cylindrocladium. Pages 107-110 and 248 in: Methods for Research on Soilborne Phytopathogenic Fungi. L. L. Singleton, J. D. Mihail, and C. M. Rush, eds. APS Press, St. Paul, MN.

Iriarte, F., Paret, M., Knox, G., Schubert, T., Jeyaprakash, A., and Davison, D. 2016. First report of boxwood blight caused by Calonectria pseudonaviculata in Florida. Plant Health Prog. 17:229-231.

Ivors, K. L., Lacey, L. W., Milks, D. C., Douglas, S. M., Inman, M. K., Marra, R. E., and LaMondia, J. A. 2012. First report of boxwood blight caused by Cylindrocladium pseudonaviculatum in the United States. Plant Dis. 96:1070.

Malapi-Wight, M., Hebert, J. B., Buckley, R., Daughtrey, M. L., Gregory, N. F., Rane, K., Tirpak, S., and Crouch, J. A. 2014. First report of boxwood blight caused by Calonectria pseudonaviculata in Delaware, Maryland, New Jersey, and New York. Plant Dis. 98:698.

Nakajima, T., Gomi, T., and Nemoto, M. 1988. Formation and isolation method of microsclerotia of Calonectria crotalariae by using cellophane layers. Annu. Rep. Plant Prot. Soc. North Jpn. 39:108-109.

Palmer, C. L., and Shishkoff, N. 2014. Boxwood blight: a new scourge, a new paradigm for collaborative research. Outlooks Pest Manag. 25:230-236.

Polizzi, G., La Rosa, R., Arcidiacono, C., and D'Emilio, A. 2003. Effects of innovative films in soil solarization for the control of soilborne pathogens. Pages 805-811 in: Proceedings of the Sixth International Symposium on Protected Cultivation in Mild Winter Climate: Product and Process Innovation, Vols 1 and 2. G. LaMalfa, V. Lipari, G. Noto, and C. Leonardi, eds.

R Core Team. 2015. R: A language and environment for statistical computing. R Foundation for Statistical Computing, Vienna, Austria.

Shishkoff, N. 2016. Survival of microsclerotia of Calonectria pseudonaviculata and C. henricotiae exposed to sanitizers. Plant Health Prog. 17:13-17.

Shishkoff, N., and Camp, M. J. 2016. The effect of different temperatures and moisture levels on survival of Calonectria pseudonaviculata in boxwood leaves and twigs and as microsclerotia produced in culture. Plant Dis. 100: 2018-2024.

Tripp, M. 2016. Boxwood blight leaves presidential library garden bare. NewsLeader, http://www.newsleader.com/story/news/local/2016/09/21/boxwoodblight-leaves-presidential-library-garden-bare/90799326/

Vitale, A., Castello, I., D'Emilio, A., Mazzarella, R., Perrone, G., Epifani, F., and Polizzi, G. 2013. Short-term effects of soil solarization in suppressing Calonectria microsclerotia. Plant Soil 368:603-617.

Ward Gauthier, N. A., Amsden, B., Beale, J., and Dixon, E. 2016. First report of boxwood blight caused by Calonectria pseudonaviculata in Kentucky. Plant Dis. 100:1019.

Weeda, S. M., and Dart, N. L. 2012. Histological evidence that microsclerotia play a significant role in disease cycle of the boxwood blight pathogen in southeastern United States and implications for disease mitigation. Plant Health Prog. doi.org/ 10.1094/PHP-2012-0403-01-BR 